7.

\title{
Die Zerstörung der Entleerungen Cholera-Kranker mittelst Salzsäure und chlorsaurem Kali.
}

\author{
Von Dr. Wiederhold in Cassel.
}

Wenn es wahr ist, dass die Entleerungen der Cholera-Kranken die Träger des Cholera-Giftes sind, so sollte man folgerichtig sein Haupt-Augenmerk darauf richten, diese mit den wirksamsten Zerstörungsmitteln zu bebandeln. Die gewöhnlichen Desinfections-Mittel erscheinen in diesem Falle nicht, sicher genug. Diejenigen unter ihnen, welche nur die Fäulniss verhindern, wie Carbolsäule, Eisenvitriol, Kohle etc. können unter Uııständen z. B. beim Ausschütten der Excremente leicht ausser Berülurung mit diesen bommen, wodurch die Wirkung natürlich aufgehoben wird. Bei einer allgemein durchgefühten Desinfection in Senkgruben und Kübeln kamn die Gefahr freilich nicht gross sein; anders jedoch da, wo Excremente in ein Kanalsystem laufen, welches keine Spülvorrichtungen besitzt, wie dieses in manchen Städten z. B. in Cassel der Fall ist. Unter den wirklich zerstörenden Mitteln wurde meines Wissens bisher unbegreiflicherweise eines nicht empfohlen, wclches die grösste Beachtung verdient. Es ist dieses die Zerstörungsmethode organischer Körper mit Salzsäure und chlorsaurem Kali, welche bei Excrementen Cbolera-Kranker nicht schwer anzuwenden sein dürfte.

Man hat zu diesem Behufe nur nöthig, die Fäcalstoffe mit roher Salzsäure - natürlich in einem Porzellan- oder Steingut-Gefäss - zu über giessen und so lange kochendes Wasser zuzusetzen, bis die Masse lauwarm geworden ist, was man durch das Handgefühl am Geschirr leicht beurtheilen kann. Alsdann setzt man 1-2 Messerspitzen voll krystallisirtes chlorsaures Kali zu. Die hierdurch stattfindende Entwickelung von Chlor und nicht näher gekannten Chlorsauerstoff-Verbindungen ist so ausserordentlich energisch wirkend auf organische Substanzen, dass diese in kurzer Zeit zerstört und alles zu einer weingelben Flüssigkeit aufgelöst wird. Man nimmt die Operation am besten im Freien oder an einem zugigen Orte vor und kann völliger Sicherheit wegen nach dem Zusatz des chlorsauren Kalis das Gefäss mit einem Brett bedecken. Dieses Verfahren, welches einfach und leicht auszuführen ist, dabei nicht im mindesten kostspielig, verdient wenigstens in allen Cholerahospitälern eingeführt zu werden. Von der Wirksamkeit dieser Zerstörungsmethode habe ich in meiner früheren Stellung als Gerichts-Chemiker mich mehrfach zu überzeugen Gelegenheit gehabt. Es fällt mittelst derselben nicht schwer, die Weichtheile einer ganzen Leiche in verhältnissmässig. kurzer Zeit zu einer klaren Flüssigkeit aufzulösen. Andere Chlorpräparate, so der Chlorkalk, selbst das gasförmige Chlor, stehen der Zerstörungsmethode mit chlorsaurem Kali und Salzsăure in ihrer. Wirkung auf organische Substanzen weit nach. 